\title{
UMA BREVE INVESTIGAÇÃO SOBRE O ETHOS CIENTÍFICO EM UM MUNDO HIPERMODERNO
}

\author{
Claudia Castro de Andrade ${ }^{1}$
}

\section{Resumo:}

Ao tratar do ethos científico, o artigo tenciona discutir os novos sentidos hipermodernos que dirigem a conduta social e, por conseguinte, o "fazer científico", por vezes limitado à prática experimental que prescinde das discussões prévias sobre suas condições sociais. Não se pretende subalternar a ciência, enquanto corpo de conhecimento, à mera condição de algo dependente do caráter social em que se encontra nem reduzir e converter a ciência a questões sociológicas, mas de destacar como o ethos científico, produto de seu contexto social e, desse modo, posterior a todo um movimento primariamente humano, pode alterar o que entendemos por ciência. Com isso, esse trabalho pretende não discorrer sobre o que é a ciência, afinal, ou sobre as estruturas que compõem as revoluções científicas, mas sobre as condições sociais e os valores intrínsecos a novas urgências, sem, no entanto, provocar a redução ingênua da metodologia científica ao que se destacou aqui como "ethos científico".

Palavras-Chave: Hipermodernidade. Cultura. Progresso Científico.

\section{A BRIEF INVESTIGATION ON SCIENTIFIC ETHOS IN A HYPERERMODERN WORLD}

\begin{abstract}
:
When dealing with the scientific ethos, the article intends to discuss the new hypermodern meanings that guide social conduct and, therefore, "scientific doing", sometimes limited to the experimental practice that dispenses with previous discussions about their social conditions. It is not intended to subordinate science, as a body of knowledge, to the mere condition of something dependent on the social character in which it finds itself, nor to reduce and convert science into sociological issues, but to highlight how the scientific ethos, product of its social context and, so, after a mainly human movement, it can change what we mean by science. With this, this work intends not to talk, after all, about what science is or about the structures that make up scientific revolutions, but about social conditions and intrinsic values to new urgencies, without, however, causing the naive reduction of scientific methodology for what stood out here as "scientific ethos".
\end{abstract}

Keywords: Hyperermernity. Culture. Scientific Progress.

\section{INTRODUÇÃ̃o}

Ao afirmar que devemos "certamente reconhecer que a natureza tem-nos mantido a urna boa distância de todos os seus segredos, só nos concedendo o conhecimento de umas poucas qualidades superficiais dos objetos" (Hume, 2004, p. 62), David Hume (1711-1776) abre o caminho para a possível instauração de uma completa descrença em qualquer estabelecimento de verdade. Afinal,

1 Doutoranda em Filosofia - linha de pesquisa: epistemologia e filosofia da ciência (UERJ-IFCH); Mestre em História das Ciências (UFRJ); Especialização em Neuropsicologia (Instituto de Neurociências Aplicadas INA); Graduação em Filosofia (UERJ-IFCH). E-mail para contato: andrade.claudia@ posgraduacao.uerj.br. https://orcid.org/0000-0003-2717-3035 
Uma coisa é saber algo sobre nós mesmos (...) outra bem diferente é saber algo sobre o mundo (...) e que não devemos incorrer no erro de supor que por sermos capazes de saber alguma coisa sobre nós mesmos (...) somos também capazes de saber algo sobre o mundo. (FREITAS, 2003, p. 10).

Certamente, tal posicionamento acerca do entendimento humano foi o meio termo entre os projetos epistemológicos com postura dogmático-fundacionista e aquilo que Renan Springer de Freitas chama de "pessimismo epistemológico imobilizador" (2003, p. 9) do ceticismo. Considerando-se que o ceticismo humiano nos alertou a hipótese de que só conhecemos por hábitos e crenças, em vista da impossibilidade de se confiar na experiência, ressaltando, ao mesmo tempo, que "o melhor meio de evitar essa confusão é sermos modestos em nossas pretensões, inclusive apontando nós mesmos a dificuldade antes que ela seja levantada contra nós" (Hume, 2004, p. 61-62), pode-se compreender a atualização do ceticismo em suas variantes contemporâneas. Como assevera Freitas (2003), "os herdeiros mais importantes do naturalismo de matriz humiana são Dewey, Wittgenstein, Quine e, obviamente, Thomas Kuhn" (Freitas, 2003, p. 29).

Nesses termos, aceitando-se a tese de que o pensamento de Hume tenha influenciado o relativismo dos pensadores pragmáticos que se destacaram no século 20 , depreende-se a crise na razão e a investigação torna-se um processo que se debruça e se determina por meio dos acordos e crenças da comunidade científica. Por outro lado, ao acatarmos sabiamente a ideia de impossibilidade de uma absoluta compreensão das coisas, fomos levados desastrosamente, a meu ver, ao imediatismo das interpretações e discursos cotidianos. Os projetos clássicos de análises históricas se tornaram obsoletos e representantes de uma velha ordem mundial pautada numa verdade nonsense. Querendo escapar do dogmatismo nos tornamos reféns de um tipo radical de relativismo, para o qual nem mesmo no campo fenomênico poderia atuar nosso limitado entendimento. Assim, repudiou-se a verdade, e a objetividade sobre o real tornou-se uma pretensão de prescrição definitivamente absoluta e deveras fundacionista.

Rasgadas as cartilhas de filosofias puristas e os manifestos caducos de pretensas narrativas históricas chegamos a um conceito de vida ressignificado e que se tonaliza com o hedonismo e as expectativas de um novo tempo de hipermodernização do mundo.

O pós de pós-moderno ainda dirigia o olhar para um passado que se decretara morto; fazia pensar numa extinção sem determinar o que nos tornávamos, como se se tratasse de preservar uma liberdade nova, conquistada no rastro da dissolução dos

\begin{tabular}{|l|l|l|l|l|}
\hline Qevista Qialeatus & Ano 10 & n. 23 & Maio - Agosto 2021 & p. $105-119$ \\
\hline
\end{tabular}


enquadramentos sociais, políticos e ideológicos. Donde seu sucesso. Essa época terminou. Hipercapitalismo, hiperclasse, hiperpotência, hiperterrorismo, hiperindividualismo, hipermercado, hipertexto - o que mais não é hiper? O que mais não expõe uma modernidade elevada à potência superlativa? Ao clima de epílogo segue-se uma sensação de fuga para adiante, de modernização desenfreada, feita de mercantilização proliferativa, de desregulamentação econômica, de ímpeto técnicocientífico, cujos efeitos são tão carregados de perigos quanto de promessas. Tudo foi muito rápido: a coruja de Minerva anunciava o nascimento do pós-moderno no momento mesmo em que se esboçava a hipermodernização do mundo. Longe de decretar-se o óbito da modernidade, assiste-se a seu remate, concretizando-se no liberalismo globalizado, na mercantilização quase generalizada dos modos de vida, na exploração da razão instrumental até a 'morte' desta, numa individualização galopante. (Lipovetsky, 2004, p. 53).

A atividade científica, tal como qualquer outra atividade humana, insere-se num mundo, cujos valores efêmeros transformam os sentidos e objetivos por meio da naturalização do fútil, do vazio e da desorientação contemporânea. No entanto, concordo com Chalmers quando este diz que "o simples fato de que a atividade científica não pode ser separada das outras que atendem a outros interesses não implica em si que o objetivo da ciência esteja subvertido" (1994, p. 159). Assim, "se a ciência como tal não pode ser qualificada moralmente, pode sê-lo, no entanto, a utilização que dela se faça, os fins e os interesses a que se serve e as consequências sociais da sua aplicação" (Sánchez Vázquez, 2001, p. 105). Qualifiquemos, pois, seu uso e aplicabilidade num período de tempo definido pelo filósofo francês, Gilles Lipovetsky, como "hipermodernidade".

\section{O UNIVERSO TECNOLÓGICO DA HIPERMODERNIDADE COMO POLO ESTRUTURANTE DA CULTURA-MUNDO}

Nos termos apresentados por Gilles Lipovetsky, hipermodernidade se define como "uma sociedade liberal, caracterizada pelo movimento, pela fluidez, pela flexibilidade; indiferente como nunca antes se foi aos princípios estruturantes da modernidade" (2004, p. 26). Pautando-se pela contradição, o mundo hipermoderno representa o grau superlativo da territorialização da desordem e do pensamento que substitui uma verdade por outra e produz o esvaziamento dos valores éticos e sua capacidade heurística de investigação das crenças e normas de conduta.

Os indivíduos hipermodernos são ao mesmo tempo mais informados e mais desestruturados, mais adultos e mais instáveis, menos ideológicos e mais tributários das modas, mais abertos e mais influenciáveis, mais críticos e mais superficiais, mais céticos e menos profundos.

\begin{tabular}{|l|l|l|l|l|}
\hline Qonista Dialectus & Ano 10 & n. 23 & Maio - Agosto 2021 & p. $105-119$ \\
\hline
\end{tabular}


Se a hipermodernidade se debruça sobre todas as esferas da vida humana não seria diferente com o universo pragmático e tecnocientífico, no qual instaurou uma moral global: a moral do hiperconsumo, da hiperindividuação, da desumanização e da reificação da consciência, transformando o universo tecnológico em polo estruturante da cultura-mundo.

Como definiu Lipovetsky em entrevista,

A hipermodernidade é um modelo teórico pensado para compreender o mundo contemporâneo principalmente por uma relação entre três lógicas fundamentais: o mercado, a tecnociência e a cultura individualista democrática. ${ }^{2}$

Nesses termos, o universo tecnocientífico ao invadir as crenças e hábitos transformou-se numa cultura hipertecnológica, uma cultura-mundo baseada na racionalização técnica e mercantil tal como um sistema integrado e organizador do mundo, expandindo-se a todos os domínios da vida. Assim, a complexidade e os processos de mundialização (culturamundo) afetam e deixam de orientar a ciência de modo a atender às necessidades da hipermodernidade e às lógicas que fundamentam sua base. Afinal, "o culto da modernização técnica prevaleceu sobre a glorificação dos fins e dos ideais” (Lipovetsky, 2004, p. 57).

Considerando-se, então, que a cultura se naturaliza no comportamento, nas crenças e nos valores humanos imprimindo sua marca, a verdade passa a ser definida pelo mercado de modo totalizante e impessoal, pois na cultura-mundo, não existem antagonismos, mas um processo de integração entre o global e o particular. A hipermodernidade não é mais um tempo de decisões inegociáveis e ideologias incontestes, mas sim um momento que se atualiza constantemente no paradoxo de uma autonomia libertária e de uma tradição que conserva valores, bem como no paradoxo entre o direito ao individualismo e a legitimidade dos discursos da coletividade, tendo em vista, como já foi dito, que na cultura-mundo o global e o fragmentado caminham juntos. O contraditório tem limites estabelecidos pelo próprio movimento das estruturas. Podemos observar que uma "uniformização globalitária e fragmentação cultural caminham a par” (Lipovetsky, 2010, p. 23), entretanto, tal fato não está, obviamente, imune às recriações de crises identitárias de segmentos específicos e fragmentados da sociedade.

Orientada pelos valores e sentidos da hipermodernidade e pela mudança de valores, a prática científica, nesse sentido, se articula com as necessidades, circunstâncias e interesses sociais nos quais valores e crenças devam ser justificados e aceitos, pois seu sucesso depende

2 LIPOVETSKY, Gilles; GANITO, Carla - Entrevista a Gilles Lipovetsky. Entrevista de Carla Ganito. Comunicação \& Cultura. Lisboa. ISSN 1646-4877.9 (Primavera-Verão 2010) 155-163

\begin{tabular}{|l|l|l|l|l|}
\hline Qenista Q Dialectus & Ano 10 & n. 23 & Maio - Agosto 2021 & p. $105-119$ \\
\hline
\end{tabular}


desse aceite, o qual vale ressaltar, não depende somente de um grupo ou comunidade científica, mas de todos nós, por meio da naturalização e do endosso de algo que se instaura na própria humanidade em sua época específica.

\subsection{Os elementos da pseudoconcreticidade}

Para que se instaurem como cultura-mundo é preciso que os polos estruturantes da hipermodernidade se territorializem no pensamento e nas ações superando a antítese entre as práticas sociais e as representações simbólicas. Assim, a mudança de valores se estabelece em várias esferas da existência humana. Na medida em que "o triunfo do hipercapitalismo não é só econômico, mas também cultural: invadiu o imaginário, os modos de pensamento, os objectivos da existência e a relação com a cultura e a educação" (Lipovetsky, 2010, P. 48).

Com isso, podemos associar a hipermodernidade a um conceito que o filósofo marxista Karel Kosik denominou "pseudoconcreticidade" 3 , cujo caráter se define por uma aparente sensação de independência, de coesão social e pelo imediatismo se naturalizando, assim, no comportamento humano e tornando-se, por isso mesmo, consentida.

O complexo dos fenômenos que povoam o ambiente cotidiano e a atmosfera comum da vida humana, que, com a sua regularidade, imediatismo e evidência, penetram na consciência dos indivíduos agentes, assumindo um aspecto independente e natural, constitui o mundo da pseudoconcreticidade. (Kosik, 1986, p. 11).

Por meio da pseudoconcreticidade, podemos dizer, portanto, que os objetivos hipermodernos, e seus respectivos polos estruturantes, descritos por Lipovetsky, se camuflam, pois não estão evidenciados na lógica de uma mediação e correspondência entre a práxis e as condições históricas pelas quais se realizam e se determinam. Como lembra Kosik, "o que confere a estes fenômenos o caráter de pseudoconcreticidade não é a sua existência por si mesma, mas a independência com que ela se manifesta" (Kosik, 1986, p. 16) e somente o pensamento dialético é capaz de revelar sua mediação e os elementos dos quais deriva.

Na hipermodernidade, essa pseudoconcreticidade, pode-se dizer, se efetiva na medida em que não é perceptível a relação entre os polos que configuram sua estrutura. A pseudoconcreticidade destaca o caráter prático, funcional e utilitário das ações humanas. No espaço da pseudoconcreticidade, o caráter de praticidade e utilidade do fazer científico permite

3 Conceito utilizado no livro Dialética do Concreto, publicado em 1963.

\begin{tabular}{|l|l|l|l|l|}
\hline Rovista Dialectus & Ano 10 & n. 23 & Maio - Agosto 2021 & p. $105-119$ \\
\hline
\end{tabular}


a sobreposição do modus operandi de suas práticas experimentais. Apartado da teoria, o prático se sobrepõe e, ao revelar a cultura do "prático" que mantém, e não da práxis que transforma 4 , a pseudoconcreticidade do mundo hipermoderno e seus polos estruturantes se territorializa e determina as características de função e utilidade prática da ciência.

A pseudoconcreticidade resulta, desse modo, na impossibilidade de percepção dos fatores que atravessam a práxis humana na hipermodernidade o que impede, vale ressaltar, qualquer possibilidade de se determinar tal mediação pela teoria. Sendo construídas de modo prático, as relações do sistema não deixam transparecer o que está implícito. Desse modo, as relações que medeiam o sistema, como as relações de poder, são tidas como inconveniências necessárias reguladas pela "consequente", e “inevitável", racionalidade objetiva e não permitem, assim, a percepção do que está no interior delas mesmas. Assim, o devenir ${ }^{5}$ histórico das estruturas sociais hipermodernas constrói hábitos, valores e se naturalizam na consciência dissolvendo-se na própria percepção forjada do indivíduo, produzindo sua incapacidade de perceber ou intuir os mecanismos mediadores, transformando-se, assim, numa percepção imediatizada e objetivamente superficial da realidade.

Por meio disto, o objeto se torna alheio ao agente, pois o agente não é capaz de perceber as inadequações constantes na relação de sua atividade com o objeto e, consequentemente, as relações de poder que lhe são impostas, pois, a "racionalidade objetiva do desenvolvimento social ou de uma determinada formação social não aparece de imediato" (Sánchez Vázquez, 1977, p. 339). A verdade, tradicional e conservadora, se transforma numa verdade liberal que autoriza, delibera, justifica e, sem nos darmos conta de sua pseudoconcreticidade, se torna legítima.

A separação das relações de poder quanto às relações de exploração e a elevação das primeiras ao plano do absoluto fazem do poder um novo fetiche. A um novo fetichismo sucumbe grande parte do pensamento atual, inclusive quando se apresenta como libertador (Sánchez Vázquez, 2001, p. 17).

Sendo a prática científica experimental algo "que se manifesta quando o pesquisador atua sobre um objeto material modificando à vontade as condições em que se opera um fenômeno" (Sánchez Vázquez, 2001, p. 199) e, por outro lado, sendo a prática social, uma "atividade de grupos ou classes sociais que leva a transformar a organização e direção da

Cf. Vázquez, 1977, p. 4.

5 Sinônimo de devir (transformação; mudança; movimento).

\begin{tabular}{|l|l|l|l|l|}
\hline Q & Ano 10 & n. 23 & Maio - Agosto 2021 & p. $105-119$ \\
\hline
\end{tabular}


sociedade, ou a realizar certas mudanças mediante a atividade do estado" (Sánchez Vázquez, 2001, p. 200), compreende-se que, o ethos científico não está, obviamente, apartado do caráter político que envolve suas práticas e urgências, na medida em que a prática científica é uma prática social. A prática científica, portanto, não está nem poderia ser subsumida numa análise menos específica, em vista de seu status próprio e característico. A própria contiguidade das práticas científicas marcadas por suas crises e consequentes revoluções tem como estímulo e munição a competição e as relações de poder.

\subsection{A práxis inintencional}

A necessidade e o incremento das forças produtivas determinam, no interior das práticas científicas, a necessidade de um aperfeiçoamento acelerado que modifica o ethos científico de modo a fazê-lo se conformar com os novos padrões hipermodernos se naturalizando quase imperceptivelmente em torno da pseudoconcreticidade na qual vivemos e sua aparente sensação de coesão social. Este fato pode ser observado durante a pandemia do Coronavírus (Covid-19) em que vários laboratórios do mundo todo competem pela nacionalidade da vacina e por quais países irão receber os primeiros lotes ${ }^{6}$. Nesses termos, vinculada à produção e à competitividade, a ciência se converte num processo, cujo sistema demanda um emergente progresso científico que atende às necessidades da cultura-mundo e, ao mesmo tempo, determina segmentos e valores. Esse ethos científico, ao mesmo tempo em que se vincula e atende aos interesses em curso torna-se, por assim dizer, sua própria produção material. Sobre isso, Sánchez Vázquez lembra que "a produção não só determina a ciência, como esta se integra na própria produção, como sua potencia espiritual, ou como uma força produtiva direta" (Sánchez Vázquez, 1977, p. 223).

A essa inversão de papéis, Sánchez Vázquez chama de “práxis inintencional”. Em outras palavras, "práxis inintencional”, seria como dizer que os homens passam a ser regulados por aquilo que eles mesmos criaram e/ou impulsionaram sem que tenham, a princípio, conspirado para isso. Assemelha-se ao que, no âmbito das comunidades científicas, Thomas Kuhn denominou de "elemento de arbitrariedade", os quais são o resultado de acidentes

\footnotetext{
6 Ver: https://www.bbc.com/portuguese/internacional-53926925.
}

\begin{tabular}{|l|l|l|l|l|}
\hline Qevista Dialectus & Ano 10 & n. 23 & Maio - Agosto 2021 & p. $105-119$ \\
\hline
\end{tabular}


pessoais e históricos capaz de formar as crenças de uma dada comunidade científica em uma época específica. Como assevera o próprio Kuhn,

\footnotetext{
Um elemento aparentemente arbitrário, composto de acidentes pessoais e históricos, é sempre um ingrediente formador das crenças esposadas por uma comunidade científica específica numa determinada época. Contudo, esse elemento de arbitrariedade não indica que algum grupo possa praticar seu ofício sem um conjunto dado de crenças recebidas. (Kuhn, 2013, p. 63).
}

Assim, nem sempre é possível estabelecer uma relação simbiótica entre aquilo que os homens intencionam e o que é produzido por eles. A produção determina, ela mesma, novas condições, necessidades e urgências, à revelia de qualquer intencionalidade ou direcionamento específico anterior. Tais necessidades e urgências poderiam, portanto, nem mesmo existir - a princípio - idealmente por alguém, mas se constituir de modo espontâneo. Desse modo, nada traduz melhor esse efeito e processo que a citação a seguir:

As mudanças de formação econômico social (...) implicam numa mudança qualitativa radical na história humana. Essa mudança ou substituição não surge historicamente como realização ou plasmação de uma intenção ou projeto de um sujeito, mas sim espontaneamente, ou seja, sem que os homens sejam conscientes de que sua atividade leva a tais resultados (Sánchez Vázquez, 1977, p. 327).

Contudo, embora a práxis inintencional crie novas formas de necessidade, são nossos valores hipermodernos que as mantém e, portanto, os possíveis elementos de arbitrariedade não implicam inexistência de práticas oriundas de crenças. Inegavelmente, todos somos, enquanto partícipes dessa mesma época, estimulados a reproduzir, intencionalmente ou não, os valores contemporâneos.

Como vimos, a prerrogativa da cultura-mundo é reduzir ou eliminar contradições e o hiato entre a práxis e a teoria, de modo a camuflar os elementos mediadores que existem entre eles. Da mesma forma, a cultura-mundo agrega conservadores e liberais sob a égide de seus polos estruturantes para o conforto e a garantia de sua plena adaptação. A hipertecnização, enquanto polo estruturante da hipermodernidade, não é senão o retrocesso causado pela extrapolação do uso e pela dependência exacerbada e naturalizada da pseudoconcreticidadee, portanto, refere-se ao ethos dominante da cultura-mundo, autorizado cada dia mais pelo otimismo ingênuo na ciência e pela utopia e voluntarismo que afetam os "novos niilistas hipermodernos".

\begin{tabular}{|l|l|l|l|l|}
\hline Rovista Q Qialectus & Ano 10 & n. 23 & Maio - Agosto 2021 & p. $105-119$ \\
\hline
\end{tabular}


A utopia hipermoderna deriva da crença no progresso e na melhoria da qualidade e expectativa de vida pautada nos avanços científicos. O reconhecimento do maquinário de valores que "alimentam" o sistema hipermoderno é fundamental no sentido de se compreender e reavaliar o papel da ciência e a responsabilidade social do cientista. Sánchez Vázquez afirma que "todas as revoluções nada mais fizeram senão substituir um poder por outro, que conserva sua função de dominação" (ibid. p. 32), desse modo, não podemos nos furtar à discussão sobre o papel que o poder exerce no ethos científico e como o poder do próprio ethos científico se expressa na sociedade. O poder imposto pela hipermodernidade e seus polos é o mais cruel, pois se naturaliza facilmente na medida em que decorre de uma relação de imanência entre o homem e seu meio cultural. É nesse ponto de vista que podemos pensar a naturalização dos valores hipermodernos. Quando o ethos científico passa a ser definido pela anomia social que não determina, de um lado, suas condições históricas e sociais e, por outro, negligencia a possibilidade de conhecimento, a ciência se fragiliza e com ela o comportamento social daqueles que a produzem.

\section{O PRESENTE HIPERMODERNO}

Como diz Lipovetsky:

Ninguém melhor do que Nietzsche conseguiu teorizar a angústia do homem moderno perante a 'morte de Deus'. Já nada é verdadeiro, já nada é bom, e quando os valores nobres perderam o seu direito de orientar a existência, o homem fica sozinho para enfrentar a vida (Lipovetsky, 2010, p. 39).

Diante disso, vale lembrar a fala de Nietzsche, na seção 12 da Primeira Dissertação de sua Genealogia da Moral, na qual ele comenta:

Hoje nada vemos que queira tornar-se maior, pressentimos que tudo desce, descende, torna-se mais ralo, mais plácido, prudente, manso, indiferente, medíocre, chinês, cristão - não há dúvida, o homem se torna cada vez "melhor"... E precisamente nisso está o destino fatal da Europa - junto com o temor do homem, perdemos também o amor a ele, a reverência por ele, a esperança em torno dele, e mesmo a vontade de que exista ele. A visão do homem agora cansa - o que é hoje o niilismo, se não isto? Estamos cansados do homem... (Nietzsche, 1998, p. 35).

Entretanto, à revelia do próprio Nietzsche, Lipovetsky considera que "não é tanto o niilismo nem o egoísmo que se propagam, mas a impotência para regular a mundialização"

\begin{tabular}{|c|c|c|c|c|}
\hline Q Rovista Dialeatus & Ano 10 & n. 23 & Maio - Agosto 2021 & p. $105-119$ \\
\hline
\end{tabular}


(2010, p. 172). Para ele, "a primazia do presente se instalou menos pela ausência (de sentido, de valor, de projeto histórico) que pelo excesso (de bens, de imagens, de solicitações hedonistas)" (Lipovetsky, 2004, p. 61).

Considerando-se as condições da pseudoconcreticidade hipermoderna, o presente produz o divórcio entre o homem e sua própria potência, não mais sob a capa da rigidez moral, mas sob o disfarce de liberdade e autonomia. A vida se pauta na liberdade e não mais nos preceitos de uma moralidade inegociável, mas sim uma moralidade sem sacrifícios, renúncias e resignações. O presente se forja e disfarça na liberação de instintos que sob o álibi da liberdade assume e se aproveitadas contradições, parecendo exaltar nossas potências vitais e os sentidos da própria existência.

Retomo a Nietzsche, entretanto, porquanto esses sentidos, aliás, podem ser articulados com aqueles que Nietzsche explicitou na seção 28 da Terceira Dissertação:

O homem, o animal mais corajoso e mais habituado ao sofrimento, não nega em si o sofrer, ele o deseja, ele o procura inclusive, desde que lhe seja mostrado um sentido, um para quê no sofrimento. A falta de sentido do sofrer, não o sofrer, era a maldição que até então se estendia sobre a humanidade $-e$ o ideal ascético lhe ofereceu um sentido! Foi até agora o único sentido; qualquer sentido é melhor que nenhum; o ideal ascético foi até o momento, de toda maneira, o 'faute de mieux' [mal menor] par excellence (...). Não se pode em absoluto esconder o que expressa realmente todo esse querer que do ideal ascético recebe sua orientação: esse ódio ao que é humano, mais ainda ao que é animal, mais ainda ao que é matéria, esse horror aos sentidos, à razão mesma, o medo da felicidade e da beleza, o anseio de afastar-se do que seja aparência, mudança, morte, devir, desejo, anseio - tudo isto significa, ousemos compreendê-lo, uma vontade de nada, uma aversão à vida, uma revolta contra os mais fundamentais pressupostos da vida, mas é e continua sendo uma vontade!... E, para repetir em conclusão o que afirmei no início: o homem preferirá ainda querer o nada a nada querer... (Nietzsche, 1998, p. 149).

A pseudoconcreticidade, desse modo, se territorializa no próprio sentido de vida através de sua fabricação ou artificialidade intencional. A rigidez moral das cartilhas maniqueístas como ideal de valores absolutos e universais e o sacrifício em nome das retóricas ideológicas já não seduzem mais. Se antes, "a primeira modernidade era extrema por causa do ideológico-político" (Lipovetsky, 2004, p. 56), hoje "nasce uma nova sociedade moderna. Trata-se não mais de sair do mundo da tradição para aceder à racionalidade moderna, e sim de modernizar s própria modernidade" (Lipovetsky, 2004, p. 56), pois "a modernidade da qual estamos saindo era negadora; a supermodernidade é integradora" (Lipovetsky, 2004, p. 57). 
Se a ascese e a rigidez moral não são mais os princípios originários do presente, o que se pode concluir é que na hipermodernidade o presente é proveniente justamente de seu oposto, pois se funda na pseudoconcreticidade das aparências de liberdade e autonomia, as quais passam a ser disfarçadamente legitimadoras de uma seleção de modelos de conduta determinada exclusivamente pelos indivíduos, no âmbito de suas individualidades e protagonismos.

O presente se mascara de potência no roteiro de suas contradições, pois os mesmos discursos e valores que prometem liberdade são os mesmos que nos aprisiona. $\mathrm{O}$ vazio se disfarça. Um vazio, cujo termo niilismo "mantém como o da 'fábula', alguns dos traços da linguagem comum: o mundo em que a verdade se tornou fábula é, de facto, o local de uma experiência que não é 'mais autêntica' do que aquela aberta pela metafísica" (Vattimo, 1985, p. 26).

A expectativa e a esperança por melhoramento demonstram os valores implícitos no que se entende por progresso científico. No entanto, o melhoramento instrumental da técnica em nossa vida prática não pressupõe o melhoramento existencial que envolve os valores humanos. Acreditando-se termos identificado o vazio da vida contemporânea serão, então, os nossos discursos identitários e práticas cotidianas que estarão no epicentro da moda, aqueles que trarão a esperança de superação da depressão do mundo. Contudo, a moda é uma doutrina corrente que, sob a desculpa da aceitação, orienta modos de conduta e, como toda doutrina, produz reações e também o vazio.

O presente, então, passa a exaltar a liberdade e as possibilidades da vida, mas uma vida prévia e de alternativas calculadamente fabricadas, cuja produção e direcionamento do gosto, do juízo e das ações fazem com que tudo se torne previsível e passível de ser controlado. Uma vida alicerçada numa inesgotável crença e dependência na ciência e seus aparatos tecnológicos, ao mesmo tempo em que se alimenta do imediatismo e da novidade de um tempo regulado pelo efêmero.

Com a vida parecendo menos ascética e disciplinar; com a conjugação do consumo global com a liberdade pautada no individualismo enquanto um sistema de valores; com o hedonismo alicerçado numa sociedade de consumo; com a esperança cada vez maior na tecnologia que favorece a mundialização do mercado para este consumo e, por fim, com a significativa diminuição da importância dada às tradicionais estruturas de normatização social, o homem se encontra menos tangenciado pela necessidade de prescrições morais, pois se 
encontra em estado de liberdade. Ainda que o homem não esteja, de fato, liberto das imposições por uma vida ideal e rigidamente moral, a ascese não é mais hodiernamente responsável no presente hipermoderno. O presente, então, se desloca e se reconfigura em virtude das emergências como um engodo necessário da cultura-mundo.

Como foi destacado aqui, o presente é parte de um processo histórico, cuja investigação merece ser efetuada, e da qual nenhuma análise deve prescindir. Como afirma Lipovetsky:

O culto ao presente se manifesta com força aumentada, mas quais são seus contornos exatos e que vínculos eles mantém com os outros eixos temporais? De que maneira se articula nesse contexto a relação com o futuro e com o passado? Convém reabrir a questão do tempo social, pois este merece mais do que nunca uma inquirição. (Lipovetsky, 2004, p. 58).

Contudo, é preciso antes que se entenda que "a liberdade não é um estado; é uma atividade histórica que cria formas correspondentes de convivência humana, isto é, de espaço social” (Kosik, 1986, p. 221). A pseudoconcreticidade, no entanto, não permite que se perceba em que condição ocorre a sedução da liberdade e da propriedade de si criando, assim, a ambiência necessária e favorável, não ao poder e à autonomia individual, mas à crença de poder e autonomia individual. Se o presente hipermoderno não possui uma normatização com base nos ideais disciplinares do passado, possui, por outro lado, uma normatização técnica e de mercantilização de todas as esferas da vida.

A crença comum num melhoramento das condições de vida por meio da evolução linear do processo científico e tecnológico modifica o próprio sentido da vida, a qual se torna refém de uma nova verdade absoluta atualizada aos moldes atuais sob o predomínio do aqui-eagora que decorre tanto do esgotamento das ideologias políticas messiânicas do passado quanto da sedução causada pela consagração, culto, primazia e coroamento do presente, cuja hierarquia nos colocaria em vantagem em relação ao passado.

Há, portanto, o predomínio do presente, em detrimento do passado e do futuro, mas eles não são nem poderiam ser descartados. A hipermodernidade transforma-se em um novo tempo de integração ou desintegração segundo a lógica do mercado, pois a tradição dos antepassados poderá ser sempre reutilizada, renovada e atualizada sob o espírito de novidade hipermoderno e sob a lógica dos acordos e das contradições.

Se antes predominavam princípios metafísicos tradicionais, o presente hipermoderno, por sua vez, se camufla na aparência de um lócus totalmente livre de ideais e

\begin{tabular}{|c|c|c|c|c|}
\hline Q Rovista Dialectus & Ano 10 & n. 23 & Maio - Agosto 2021 & p. $105-119$ \\
\hline
\end{tabular}


das convenções estéticas e morais. Ele surge num momento em que a pauta se funda nos discursos e práticas do cotidiano sem qualquer compromisso epistêmico com a revelação da verdade parecendo, por isso, não prescrever ou orientar, mas sim afirmar potencialmente a vida. Assim, o presente hipermoderno se disfarça de potência, na medida em que finge estar desligado do maniqueísmo e da orientação de antes. A sensação, embaçada pela pseudoconcreticidade, de um mundo no qual parecem prevalecer as criações humanas impede o homem hipermoderno de perceber que, embora não pareça, o vazio continua e a promessa de autenticidade não se cumpre, na medida em que nossa consciência ainda é refém dos valores e domínios de nossas instituições morais.

Com a racionalidade prática e instrumentalmente aplicada através da busca pelo poder, da otimização da vida e do bem-estar a qualquer preço, a ciência torna-se imperativa na construção de novos hábitos, revelando sua essência metafísica. Como afirma Raymond Aron, “a religião não é apenas o núcleo primitivo do qual saíram, por diferenciação, regras morais e regras religiosas, no sentido estrito; é também a origem primitiva do pensamento científico" (Aron, 2003, p. 515).

As crenças humanas, como vemos, mudam o princípio originário do monopólio da

verdade, mas sobrevivem e se ressignificam. É assim que a crença no sentido religioso ou naturalista encontra razão de ser na crença ingênua de um progresso científico. A verdade é um princípio regulador e é através desse desejo de encontrar a verdade que inevitavelmente o cientista se debruça. Como lembra Gilles Lipovetsky, "a fé no poder da razão e da técnica alimentou o dogma do progresso necessário, linear e sem fim” (Lipovetsky, 2010, p. 54-55).

\section{REFERÊNCIAS}

ARON, R. As etapas do pensamento sociológico. Tradução de Sérgio Bath. São Paulo: Martins Fontes, 2003.

CHALMERS, A. F. O que é ciência, afinal? Tradução de Raul Fiker. São Paulo: Brasiliense, 1993.

a fabricação da ciência. São Paulo: Editora da Universidade Estadual Paulista, 1994.

\begin{tabular}{|l|l|l|l|l|}
\hline Qevista Dialectus & Ano 10 & n. 23 & Maio - Agosto 2021 & p. $105-119$ \\
\hline
\end{tabular}


HUME, D. Investigações sobre o entendimento humano e sobre os princípios da moral. São Paulo: Editora Unesp, 2004.

FREITAS, R. S. Sociologia do conhecimento, pragmatismo e pensamento evolutivo. Bauru, SP: EDUSC, 2003.

GIACOIA JR, Oswaldo. Nietzsche: fim da metafísica e os pós-modernos. In: Metafísica Contemporânea, por Guido Imaguire, Custódio Luis S. Almeida, Manfredo Araújo de Oliveira (Org.), p. 13-39. Rio de Janeiro: Vozes, 2007.

KOSIK, K. Dialética do concreto. Tradução de Célia Neves e Alderico Toríbio. Rio de Janeiro: Editora Paz e Terra, 1986.

KUHN, T. A estrutura das revoluções científicas. Tradução de Beatriz Vianna Boeira e Nelson Boeira. São Paulo: Perspectiva, 2013.

LIPOVETSKY, G. A cultura-mundo: resposta a uma sociedade desorientada. Tradução de Victor Silva. Edições 70, 2010.

Os tempos hipermodernos. Tradução de Mário Vilela. São Paulo: Editora Barcarolla, 2004.

O império do efêmero: a moda e seu destino nas sociedades modernas. Tradução de Maria Lúcia Machado. São Paulo: Companhia das Letras, 2009.

LIPOVETSKY, Gilles; GANITO, Carla - Entrevista a Gilles Lipovetsky. Entrevista de Carla Ganito. Comunicação \& Cultura. Lisboa. ISSN 1646-4877.9 (Primavera-Verão 2010) 155163.

NIETZSCHE, F. Obras Incompletas. Tradução de Rubens R. T. Filho. Col. Os Pensadores. São Paulo: Abril Cultural, 1978.

\begin{tabular}{|l|l|l|l|l|}
\hline Qovista Dialectus & Ano 10 & n. 23 & Maio - Agosto 2021 & p. $105-119$ \\
\hline
\end{tabular}


Genealogia da Moral: uma polêmica. Tradução de Paulo César Lima de Souza. São

Paulo: Companhia das letras, 1998.

SÁNCHEZ VÁZQUEZ, A. A filosofia da práxis. Tradução de Luiz Fernando Cardoso. Rio de janeiro: Paz e Terra, 1977.

Ética. Tradução de João Dell'Anna. Rio de Janeiro: Editora Civilização Brasileira, 2008

Entre a realidade e a utopia. Tradução de Gilson B. Soares. Rio de Janeiro: Editora Civilização Brasileira, 2001.

VATTIMO, G. La fin de La modernitè: nihilisme et herméneutique dans la culture postmoderne. Traduit de L'italien par Charles Alunni. Garzanti Editore, 1985. 